\title{
Histórias e cosmologia indígenas no Popol vuh, livro maia-quiché
}

\author{
Eduardo Natalino dos Santos
}

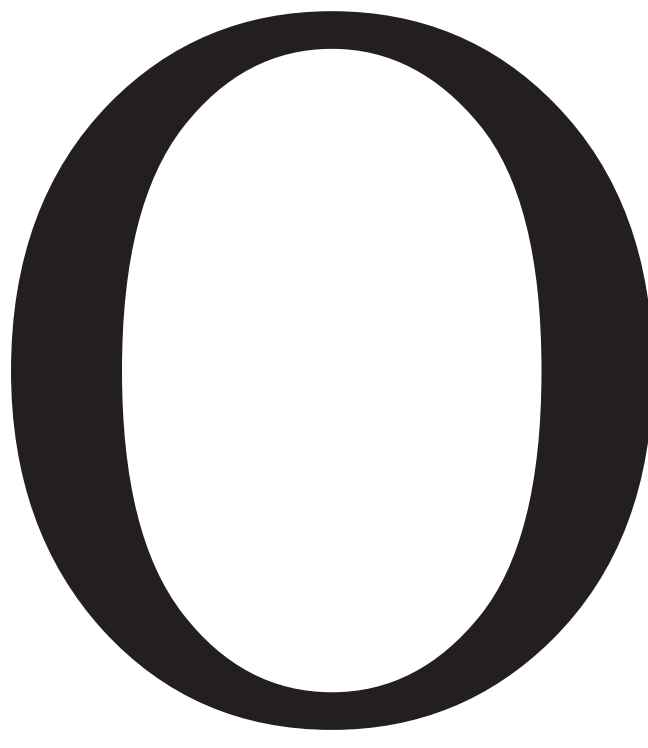

A LONGA HISTÓRIA DOS POVOS MAIAS

s cerca de 6 milhões de indígenas maias que atualmente vivem no sudeste do México - estados de Chiapas, Tabasco, Campeche, Iucatã e Quintana Roo -, em Belize, na Guatemala e nas porções oeste de Honduras e El Salvador são os descendentes e atuais construtores de uma cultura e de tradições de pensamento que podem ser estudadas ao longo dos últimos 3 mil anos, pelo menos. Nessa longa trajetória, as famosas cidades maias do período clássico (século II ao IX), como Tikal, Palenque e Yaxchilán, marcam

\section{EDUARDO NATALINO DOS SANTOS}

é professor de História da América Pré-Hispânica e História Indígena Colonial do Departamento de História da FFLCH/USP. 


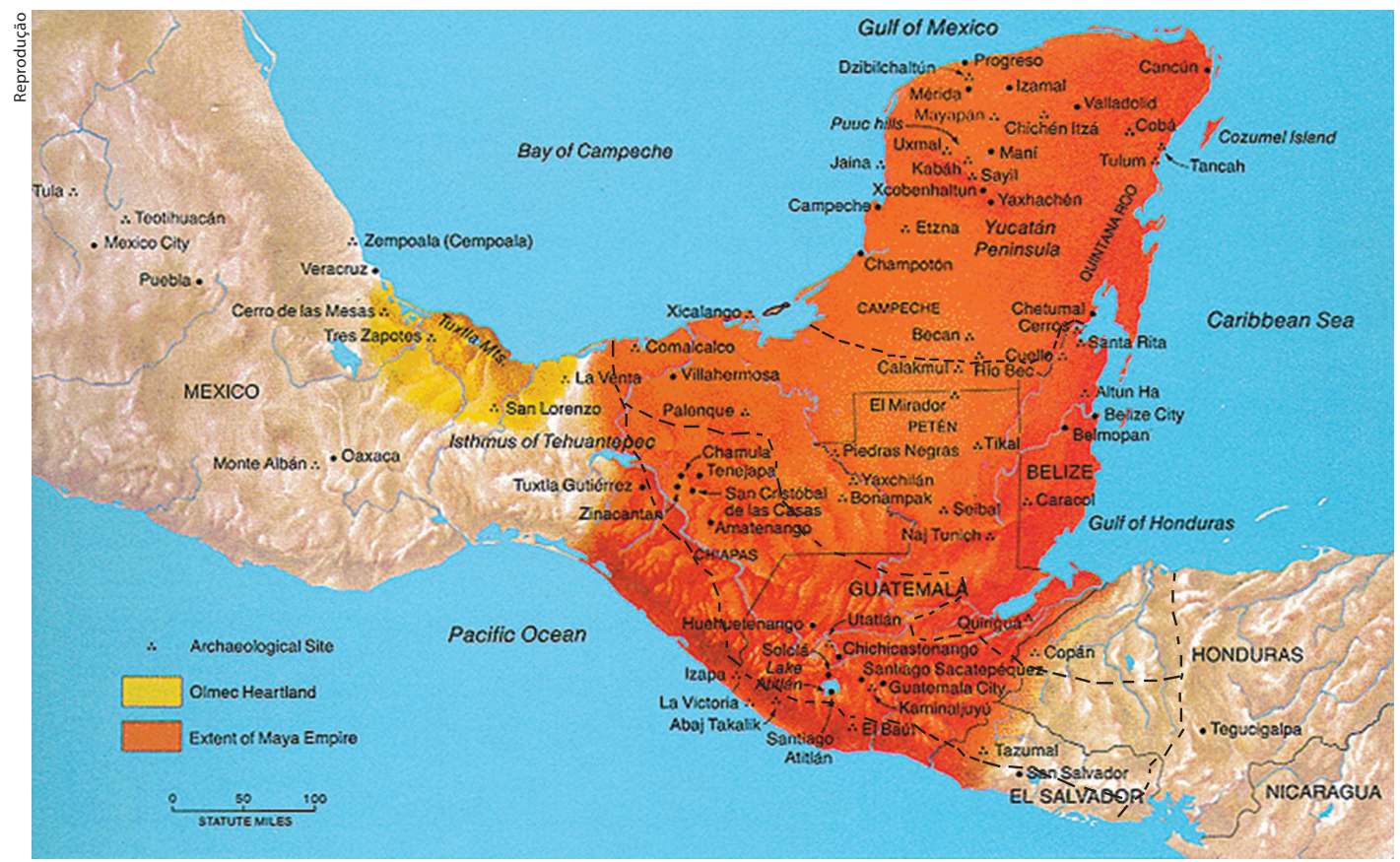

Mapa da região maia, com as divisões entre terras baixas do norte, terras baixas do sul, terras altas de Chiapas e Guatemala

apenas uma de suas fases históricas, caracterizada pela acentuada ascensão de poderosas elites governantes e guerreiras, as quais, em constante disputa pela grandiosidade de suas cidades e domínios tributários, contribuíram para o estabelecimento de fortes tensões políticas entre as mais de 30 capitais maias e entre essas capitais e as centenas de cidades ou vilas sujeitas a elas.

Antes dessas cidades monumentais do período clássico, milhares de comunidades maias com organizações sociopolíticas menos hierárquicas e edificações menos monumentais já se distribuíam na região que mencionamos de início, principalmente na região sul da atual Guatemala. Foi em meados desse milênio que algumas dessas comunidades optaram pela constituição de cidades monumentais, como Izapa e El Mirador, uma das maiores cidades do mundo em seu tempo. Esse processo resultou na tributação e na ingerência política sobre as comunidades menos hierárquicas e monumentais, fazendo que, muitas delas, também passassem a se associar e a constituir cidades de grande porte para garantirem alguma autonomia política ou mesmo para competirem de modo mais simétrico com as grandes cidades. Essa disseminação de organizações sociopolíticas hierárquicas, de monumentalidade e de conflitos por tributos caracterizou a história maia no período clássico e, certamente, acentuou a tensão entre elites e população comum, o que teve um papel relevante no declínio e queda de centenas de cidades maias que haviam se desenvolvido nas terras baixas do centro e sul, as quais foram destruídas ou simplesmente abandonadas a partir do século IX.

A etapa seguinte da história maia, ou seja, o período pós-clássico (século IX ao XVI), foi marcada por amplas migrações 
que partiram das antigas cidades decaídas, destruídas ou abandonadas e se dirigiram para o norte ou para o sul, transformando o norte da península do Iucatã e as terras altas de Chiapas e Guatemala nas principais áreas de emergência de novas cidades e confederações ou de ressurgimento de antigas. Algumas novas capitais maias procuraram e conseguiram ocupar o papel de suas predecessoras do período clássico, como Chichén Itzá ou Uxmal, sem, no entanto, obterem um êxito muito duradouro, pois também foram abandonadas ainda em meados do período pós-clássico. Ao final desse período, isto é, no início do século XVI, quando os espanhóis chegaram à região maia, vindos do altiplano central mexicano ou das ilhas do Caribe, predominavam as confederações políticas de menor porte, alcance regional e expressão monumental, nas quais as vilas e cidades principais cobravam tributos e mantinham alguma precedência política sobre comunidades menos poderosas.

Esse é, em linhas muito gerais, o mundo maia que entrou em contato, confronto e conversação com os cristãos espanhóis, que passaram a chegar às terras baixas do norte, no Iucatã, a partir de 1511, e às terras altas de Chiapas e Guatemala a partir de 1524 , onde os maias-quichés, produtores do Popol vuh, eram uma das principais forças políticas desde sua capital, a cidade de Gumarcaah ou Utatlán. Enquanto no altiplano central mexicano uma ampla coalizão formada por cerca de 50 cidades indígenas e por espanhóis derrotou os astecas em 1521 e gerou uma mudança política que contava com abrangente apoio local, na região maia, as alianças conquistadoras entre indígenas e espanhóis deflagraram guerras muito mais pulverizadas e longas contra as modestas confederações maias. Além disso, os resultados das eventuais vitórias de espanhóis e aliados indígenas, como a que se deu sobre os quichés, se mantiveram restritos a pequenas regiões por décadas e abrangiam conjuntos bastante limitados de comunidades maias, as quais, ademais, percebiam essa reordenação política como ilegítima e, frequentemente, se rebelavam contra ela.

Desse modo, o início do período colonial na região maia é marcado por um alto índice de conflitos bélicos com os cristãos, especialmente nas imediações do Lago Atitlán, onde viviam os maias-quichés que produziram o Popol vuh, e no norte da península do Iucatã. Com exceção dessas duas pequenas áreas, no restante da região maia predominavam as comunidades e confederações relativamente autônomas, ou que mantinham contatos seletivos com as vilas dominadas pelos espanhóis e aliados indígenas, isto é, em toda porção territorial ao norte da região do Lago Atitlán e de Gumarcaah, onde os maias-quichés haviam sido derrotados, e em toda a área das terras baixas do centro e sul - essa região havia sido dominada pelas cidades monumentais do período clássico e agora era ocupada pelo maias-itzaes, que migraram desde o norte da península, fugindo dos domínios espanhóis, e fundaram uma nova confederação ao sul, que se manteve autônoma frente aos poderes coloniais espanhóis até 1697.

\section{A PRODUÇÃO E OS USOS DO POPOL VUH}

O Popol vuh nos apresenta uma instigante narrativa com a perspectiva dos maias-quichés de meados do século XVI sobre a 
longa e movimentada história que esboçamos acima. Sua narrativa foi produzida com base em livros e registros anteriores, os quais, por sua vez, derivavam de tradições de pensamento e sistemas de escritura e calendários próprios e com pelo menos dois milênios de existência. Como mencionamos, desde o período pré-clássico, algumas comunidades maias passaram a adotar formas de organização sociopolíticas mais hierárquicas e com forte expressão monumental, as quais atestam suas relações com outras macroetnias ameríndias, que haviam começado a empreender esse caminho antes, como os zapotecas, da região do istmo de Tehuantepec e leste do atual estado mexicano de Oaxaca. Na região do istmo de Tehuantepec, durante o I milênio a.C., se consolidaram alguns sistemas e tradições que marcariam o repertório cultural não apenas de zapotecas e maias, mas também de outras macroetnias indígenas, como os nahuas, e que, além disso, se tornariam bastante disseminadas e presentes no milênio seguinte e em uma área ainda mais ampla, que tem sido chamada de Mesoamérica. Es- tamos nos referindo à monumentalidade que mencionamos antes, mas também a certo sistema de calendário e a sistemas aparentados de escritura pictoglífica, que foram empregados em toda essa macrorregião cultural até o período colonial, época em que o alfabeto latino passou a ser paulatinamente adotado pelos povos indígenas mesoamericanos.

Mais do que apenas uma forma de contar o tempo e de registrar informações, os sistemas de calendário e de escritura eram conjuntos de princípios interdependentes que geravam um modo de pensar, de se relacionar e de representar o mundo que hoje chamamos de natural e social, ou seja, eram um modo de produzi-lo. Nesse sentido, contar o tempo por meio de períodos de 13 ou 20 dias, de nove noites, de anos de 260, 360 e 365 dias, e de conjuntos de 52 anos e seus múltiplos, os quais formavam períodos que abrangiam dezenas de milhares de anos ou mesmo milhões de anos em alguns casos, não era apenas uma forma de quantificar matematicamente o transcurso do tempo, mas era principalmente um modo de pensar sobre os atributos e

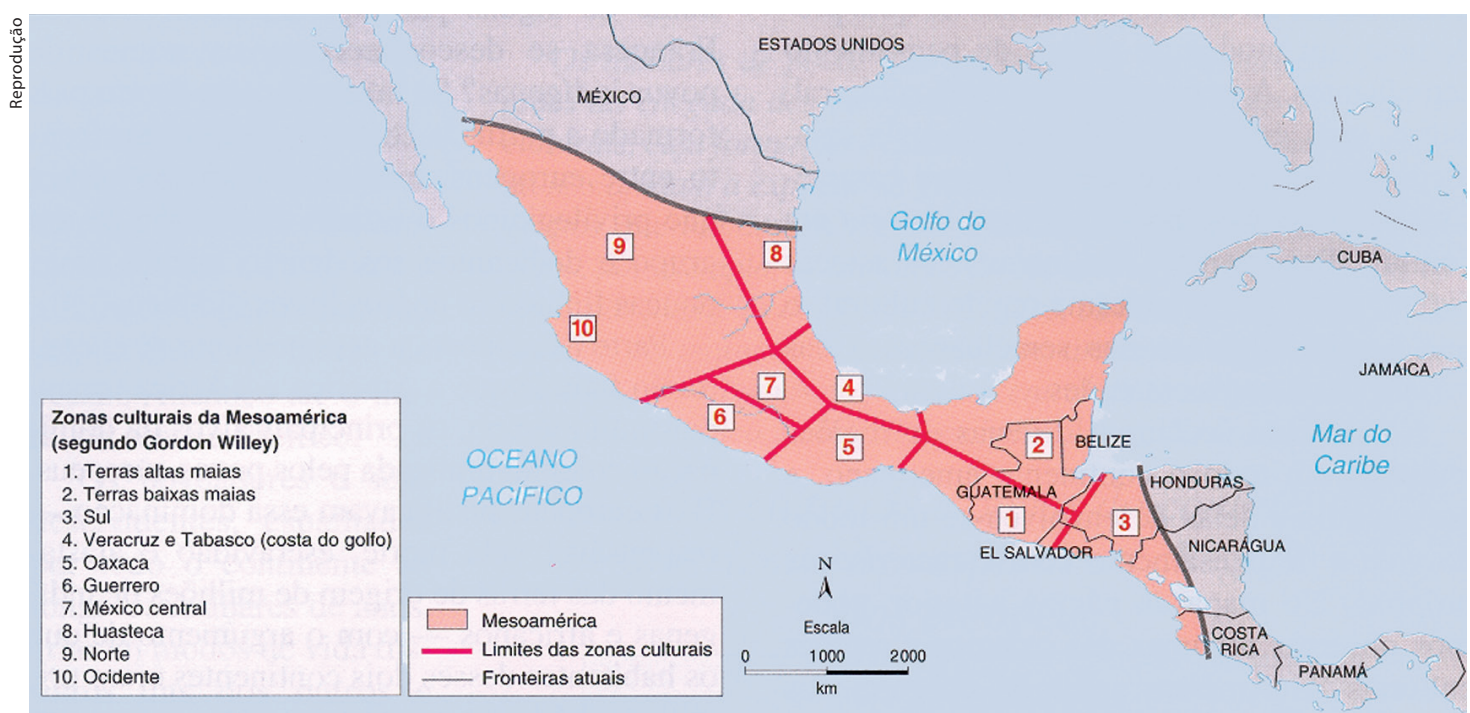

Mapa da Mesoamérica. Adaptado de: G. Duby (dir.), Atlas historique Larousse (Paris, 1987) 
qualidades do tempo e, com isso, compreender os eventos pretéritos, presentes e futuros. No mesmo sentido, produzir registros escritos sobre lápides de pedra, paredes, cerâmicas, papéis ou peles de animais empregando glifos fonéticos e ideográficos em conjunção com imagens figurativas não significava apenas registrar conteúdos que seriam reabilitados depois por um leitor, mas significava criar um mundo, dar face, corpo e existência aos entes, eventos e conceitos que habitariam esses registros escritos e pintados.

Entre esses registros, estavam manuscritos conhecidos atualmente como códices mesoamericanos. Os códices eram registros pictoglíficos portáteis e de produção e uso típicos das elites da Mesoamérica desde pelo menos o I milênio a.C. Eram confeccionados com papel amate ou papel maguey - produzidos a partir da casca interna de um tipo de figueira e das fibras de cactos da família do agave, respectivamente -, ou com peles de animais, principalmente de veados. As folhas ou lâminas de peles eram coladas e dispostas de modo a formarem longas faixas ou tiras, que eram dobradas como biombos e resultavam, quando dobradas, em formatos quadrangulares ou retangulares. Fossem de papel ou de pele de animais, essas bandas ou tiras recebiam uma fina camada de estuque branco para uniformizar a superfície e prepará-la para a pintura dos glifos fonéticos e ideográficos e das imagens, sempre delineados com traços negros, que compunham as formas que seriam preenchidas de cores, com certa predominância de tons vermelhos. Essas composições pintadas-escritas poderiam ocupar apenas um ou os dois lados do manuscrito e eram realizadas por especialistas no sistema escriturário e pictórico, que trabalhavam em conjunto com sábios e governantes das elites dirigentes. Os escritores do Popol vuh afirmam que sua narrativa em maia-quiché e que emprega o alfabeto latino fundamenta-se em leituras e consultas desses antigos códices pictoglíficos, semelhantes aos raros códices maias pré-hispânicos que nos chegaram e que procedem das terras baixas do Iucatã: o Códice de Dresden, o Códice Paris e o Códice Madri. Essas tradições

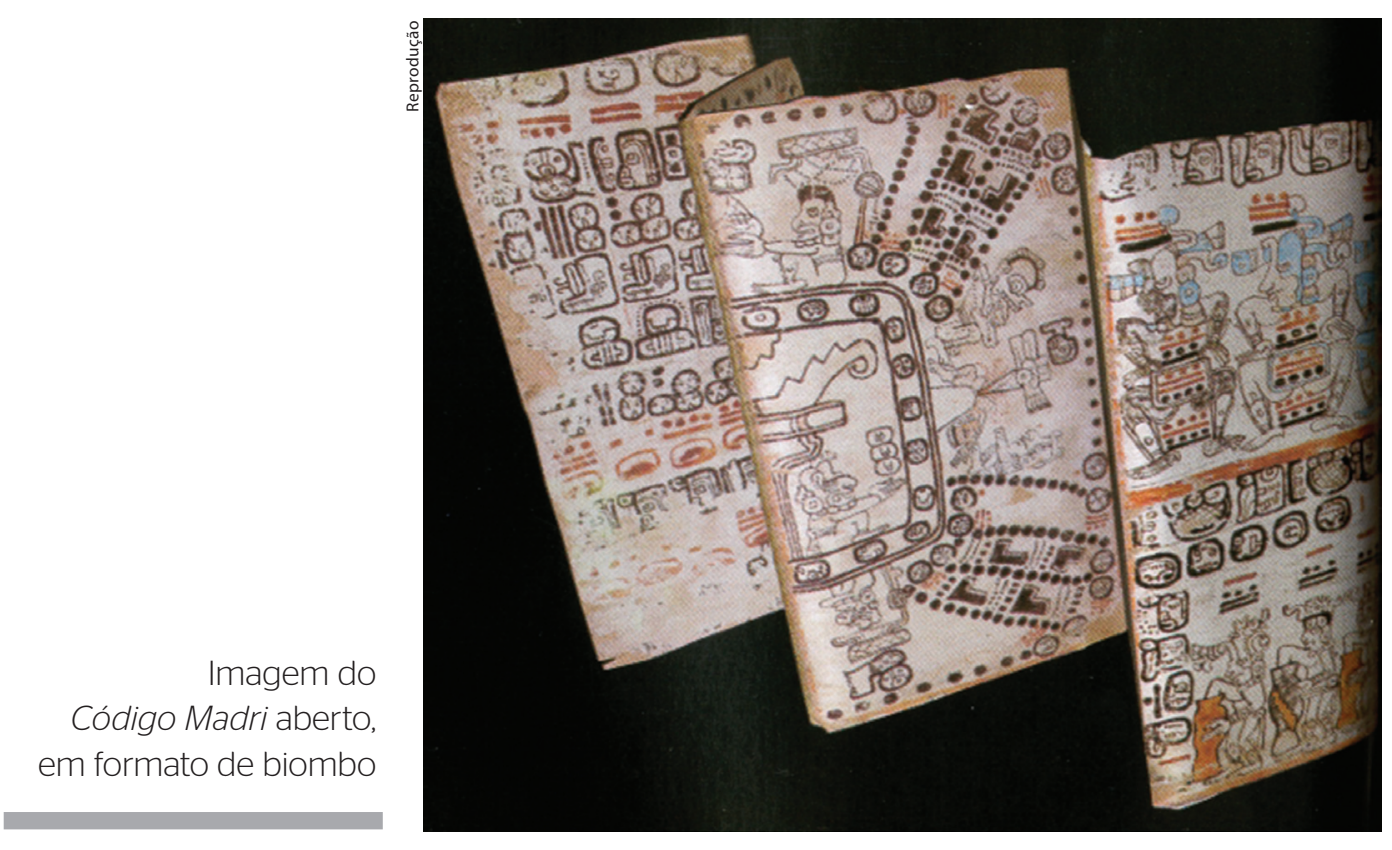


pré-hispânicas de pensamento e escrita estão fortemente presentes no Popol vuh, cujo emprego do alfabeto latino deve-se às guerras, conflitos e negociações entre quichés e espanhóis. Vejamos como isso ocorreu.

Os quichés e outros povos maias das terras altas de Chiapas e Guatemala, como rabinales e cakchiqueles, mantinham intercâmbios comerciais e diplomáticos com os indígenas nahuas do centro do México, como os astecas, por exemplo. Assim, logo após a derrota dos astecas, em 1521, uma expedição de conquista formada por tlaxcaltecas, espanhóis e também astecas partiu do centro do México, seguiu rotas e caminhos indígenas bastante conhecidos e chegou à região maia-quiché entre 1523 e 1524. Seu objetivo era derrotar os maias-quichés, que seriam antigos aliados dos derrotados astecas e os principais senhores políticos e tributadores dessa região naquele momento. Essa expedição contava com uma aliança previamente estabelecida com os maias-cakchiqueles, vizinhos que teriam sido derrotados pelos quichés algumas décadas antes e que, nesse momento, estariam subordinados a eles. Assim, de modo relativamente rápido, os quichés foram vencidos por essa coalizão que os derrotou em Gumarcaah ou Utatlán, sua capital. No entanto, a vitória dos cristãos-ibéricos e seus aliados indígenas nahuas se mostrou frágil e territorialmente bastante circunscrita. Seus aliados locais, os cakchiqueles, logo se rebelaram contra os espanhóis e, embora os cakchiqueles tenham sido derrotados em Iximché, sua capital, nunca foram totalmente vencidos, pois se evadiram e migraram para regiões próximas, onde resistiram por décadas ao domínio político espanhol.
É nesse contexto que frades dominicanos passaram a se estabelecer em Gumarcaah e Iximché e que as tradições de escrita e pensamento maia tiveram contato com as cristãs. Com o resguardo de vitórias bélicas precedentes nessas localidades, esses missionários atuavam junto aos quichés e aos cakchiqueles. Mesmo assim, essa atuação ocorria de modo relativamente negociado com as elites maias locais, tentando evitar conflitos e rebeliões, pois esses enclaves de presença espanhola estavam cercados por vilas, cidadelas e confederações maias politicamente autônomas. Nesse ambiente, os conflitos e negociações impulsionaram o trasvase e transposição de registros produzidos em um sistema de escritura a outro e as histórias e cosmologias de uma tradição de pensamento a formas mais inteligíveis para a outra. Desse modo, o Popol vuh, literalmente, Livro da comunidade, é uma nova e, ao mesmo tempo, tradicional história e cosmologia maia-quiché e traz marcas dessas negociações e conflitos com os cristãos: narrado no idioma quiché, mas registrado com o alfabeto latino; destinado provavelmente a autoridades civis e religiosas cristãs, mas com um conteúdo cosmológico e histórico bastante apegado às tradições maias; reconhece certas vitórias do deus cristão, mas reafirma a validade da cosmologia e da história dos quichés e seus vizinhos, como veremos abaixo.

A produção pelos maias-quichés de uma narrativa em alfabeto latino que abrange desde a constituição de humanidades anteriores, passa pela criação da humanidade atual, a dos homens e mulheres feitos de massa de milho, como os próprios quichés, e chega até a história dos próprios narradores e seus principais governantes e linhagens foi, cer- 
tamente, parte de negociações e conflitos entre esses indígenas e os cristãos de meados do século XVI. Trata-se de uma fórmula amplamente usada nesse tipo de contexto colonial pelas comunidades indígenas maias para obter, por exemplo, o reconhecimento de seus territórios junto às autoridades espanholas, cujo poder estava, pouco a pouco, se afirmando no mundo maia, especialmente por conta das epidemias que diminuíam a magnitude das populações indígenas de modo acentuado e, consequentemente, as abrangências territoriais e poderes políticos das comunidades maias. Contar a própria história era um modo ou tentativa de pleitear o controle de certo território e a legitimidade das autoridades indígenas frente às autoridades espanholas ${ }^{1}$.

O manuscrito original do Popol vuh foi composto por volta de 1544 e não se sabe se ele chegou a ser efetivamente usado em algum processo ou demanda com os objetivos que mencionamos acima. É certo que foi guardado e tutelado pelos quichés do ramo cavec de geração a geração e apresentado por eles ao frade dominicano Francisco Jiménez depois de 1688, data em que o missionário chegou à Guatemala. O frei Jiménez, versado no idioma quiché, estudou o manuscrito original do Popol vuh, hoje desaparecido, o transcreveu na própria língua quiché e adicionou sua versão em espanhol ao lado. Esse manuscrito produzido por Jiménez encontra-se atualmente na Biblioteca Newberry, em

1 Esse contexto de produção do Popol vuh é bastante particular às regiões em que os espanhóis haviam obtido vitórias bélicas algo significativas e, como mencionamos, não deve ser universalizado automaticamente para todo o mundo maia dos séculos XVI e XVII.

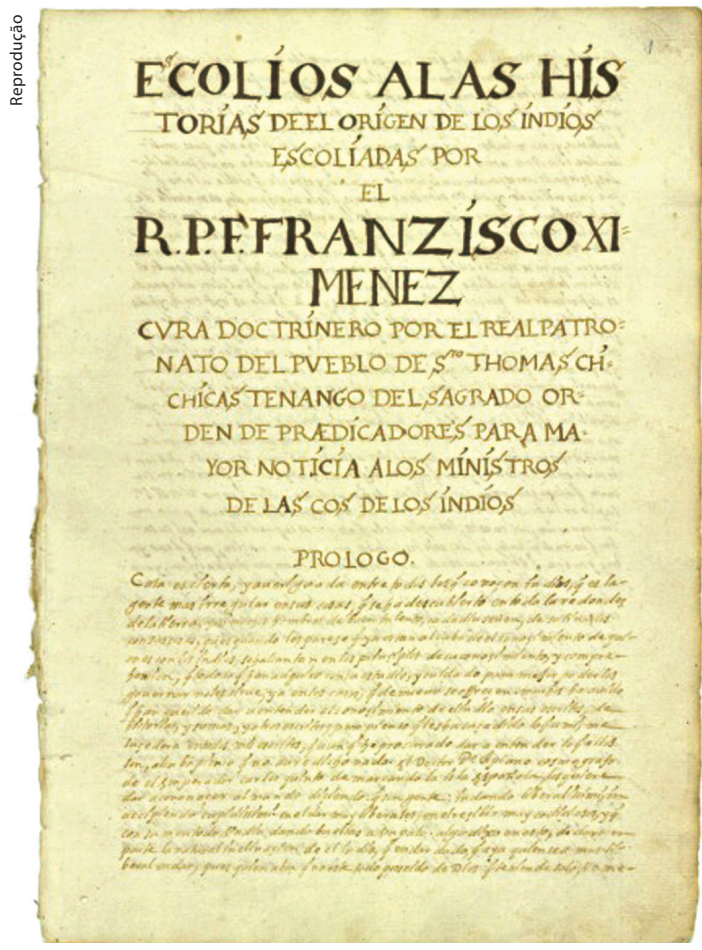

Primeira página do manuscrito do Popol vuh. Fonte: https://www.newberry.org/ popol-vuh-wuj-online

Chicago $^{2}$. Além disso, Jiménez o traduziu novamente em 1722 e o incluiu na sua Historia de la provincia de San Vicente de Chiapa y Guatemala. Seus trabalhos estiveram depositados na biblioteca do Convento de São Domingo até 1830, de onde passaram à Universidade da Guatemala e foram estudados e publicados em 1857 por Karl Scherzer e, depois, levados à França por Charles Étienne Brasseur de Bourbourg, que o traduziu ao francês e o publicou em 1861. Desde então, o Popol $v u h$ foi traduzido para muitas outras línguas ocidentais e também para algumas línguas orientais, podendo ser considerado

2 Uma excelente versão digital desse manuscrito pode ser acessada na World Digital Library: https://www. wdl.org/en/item/19995/view/1/1/. 
a cosmologia e história ameríndia mais traduzida, publicada e lida.

\section{PRINCIPAIS TEMAS E BREVE SÍNTESE DO POPOL VUH}

O manuscrito do Popol vuh não possui claras divisões internas em capítulos ou partes. Possui apenas, na versão em espanhol que consta ao lado do texto em maia-quiché, alguns espaçamentos mais amplos entre certos parágrafos, os quais separariam certas unidades narrativas ou capítulos. Geralmente, as traduções e edições modernas do manuscrito de Jiménez valorizam essa divisão do texto em capítulos, que costumam ainda ser numerados e agrupados em quatro partes precedidas por um pequeno preâmbulo. Esse agrupamento dos capítulos em quatro partes se justificaria pela existência de quatro grandes ciclos narrativos do Popol vuh, como veremos na sequência.

No preâmbulo, além da menção a um Livro da comunidade mais antigo, que já não se poderia mais consultar e que, como dissemos, seria um códice pictoglífico, anuncia-se o objetivo mais amplo da narrativa: a formação da superfície da Terra e da abóboda celeste, precisamente divididas em quatro regiões, e a vida dos seres vindouros, dos nascidos e das nascidas na luz. Além disso, esse preâmbulo apresenta uma relação bastante completa dos nomes e títulos dos deuses que teriam participado do princípio da vida e da história dos quichés: Tzacol (Criador) e Bitol (Formador); Alom (A-que-Concebe) e Qaholom (O-que-Gera); Hunahpú-Vuch (Um Zarabataneiro-Gambá) e Hunahpú-Utiú (Um Zarabataneiro-Coiote); Zaqui-Nimá (Grande Caititu Branco) e
Tziís (Quati); Tepeu (Majestade) e Gucumatz (Serpente Emplumada); u Qux Cho (Coração do Lago) e u Qux Paló (Coração do Mar); Ah Raxá Lac (O-do-Prato-Verde) e Ah Raxá Tzel (O-da-Tigela-Azul); Iyom (A Parteira) e Mamon (O Patriarca), chamados de Ixpiyacoc e Ixmucané, A-que-Ampara, O-que-Protege, Duas Vezes Parteira, Duas Vezes Avô ${ }^{3}$.

Após esse breve preâmbulo, os capítulos da primeira parte trazem uma detalhada descrição da formação do céu e da Terra, de sua repartição precisa em quatro partes ou regiões, da criação das águas e montanhas, dos vegetais, dos guardiões das matas e arbustos e dos animais, a quem os entes criadores dão vozes e pedem que honrem e invoquem os seus criadores. Estaríamos, aqui, diante de uma primeira criação: a dos animais. Mas, por não terem falado como pessoas de um mesmo grupo, pois cada um teria sua própria e diferente voz, os primeiros animais foram mudados pelos deuses, que os enviaram a morar nos grotões e florestas e decidiram que eles teriam suas carnes comidas pelos seres humanos que ainda seriam criados.

Buscando a criação de seres que os invocassem e alimentassem, os deuses resolveram conceber um ser humano de terra e barro. Mas a obra não saiu como planejada, pois esse ser humano de terra ficou encharcado, aguado e mole. Além disso, sua cabeça não virava, sua vista estava encoberta e seu rosto sempre estava voltado para um

3 Neste artigo, os nomes de lugares e personagens constantes no Popol vuh estão grafados e traduzidos de acordo com o proposto em: Popol vuh - O esplendor da palavra antiga dos Maias-Quiché de Quauhtlemallan: aurora sangrenta, história e mito, tradução crítica e notas de Josely Vianna Baptista, São Paulo, Ubu, 2019. 
mesmo lado. Apesar disso, esse ser humano falava, mas suas palavras não tinham sentido e os deuses resolveram desfazê-lo e consultar adivinhos sábios e idosos para saber como produzir seres humanos que os sustentassem e alimentassem, que os invocassem e deles se recordassem. O casal de adivinhos, Ixpiyacoc e Ixmucané, lança e consulta os grãos de milho e de tzité e a resposta é: buscar boa madeira para entalhar os novos homens.

Esses homens e mulheres de madeira povoaram a Terra e se multiplicaram, mas não tinham coração, alma nem entendimento, não se recordavam dos criadores, iam e vinham sem rumo, arrastando-se sobre mãos e joelhos e, por isso, foram também aniquilados, destruídos e desfeitos com um grande dilúvio de resina ardente. Além dessa chuva de resina, os animais e objetos que esses seres humanos teriam maltratado em vida passam a atacá-los. Apesar dessa destruição em massa, alguns desses seres humanos, desfigurados por esses ataques e cataclismo, teriam sobrevivido e dado origem aos macacos-aranhas.

Em seguida, ainda em sua primeira parte, o Popol vuh apresenta as atuações de Hunahpú (Um Zarabataneiro) e Ixbalanqué (Jaguar-Sol-Oculto), deuses gêmeos que derrotaram Vucub-Caquix (Sete Arara) e seus dois filhos, Zipacná (O Jacaré) e Cabracán (O Terremoto), os quais criavam e derrubavam montanhas somente para se vangloriarem. Em um mundo ainda sem Sol e Lua, Sete Arara se proclamava o próprio Sol e Lua para a linhagem dos seres humanos

4 Grãos vermelhos com formato semelhante aos grãos de feijão. Frutificam em uma árvore de médio porte chamada árvore-de-coral. de madeira. No entanto, ele não seria um ente verdadeiramente prodigioso, um deus autêntico, portanto, mas apenas um ser que se vangloriava e se cobria de riquezas para parecer fulgurante.

A centralidade desses gêmeos na narrativa do Popol vuh é tamanha que toda sua segunda parte é dedicada a narrar seus nascimentos, a apresentar sua mãe, Ixbaquiyalo (A-dos-Ossos-Atados) e a relatar as vidas e aventuras de seu pai e um parceiro de lutas e aventuras: Hun-Hunahpú (Um Hunahpú) e Vucub-Hunahpú (Sete Hunahpú). A trama central das vidas de Hun-Hunahpú (Um Hunahpú) e Vucub-Hunahpú (Sete Hunahpú), ambos chamados de pais dos gêmeos, consiste em uma viagem ao Xibalbá, o Mundo de Abaixo e reino dos senhores dos mortos. Eles são convidados a adentrarem o Xibalbá por incomodarem constantemente os seus senhores principais, Hun-Camé (Um Morte) e Vucub-Camé (Sete Morte), pois jogavam bola frequentemente sobre suas cabeças, gerando ruídos e incômodos no Mundo de Abaixo. Lá, Hun-Hunahpú e Vucub-Hunahpú são expostos a uma série de desafios, provações e burlas e não se saem bem. Os dois são mortos pelos senhores do Xibalbá, mas Hun-Hunahpú, ao morrer decapitado, realiza o prodígio de engravidar uma jovem senhora do próprio Xibalbá, Ixquic (Jovem Sangue Lua), com sua saliva, que é cuspida da sua cabeça pendurada em um pé de cabaça na mão da jovem que pretendia colher um dos frutos. Diante dos problemas que essa gravidez inexplicável the gera com seus pais e senhores do Xibalbá, Ixquic foge para o mundo da superfície e procura sua sogra para dar à luz aos gêmeos Hunahpú (Um Zarabataneiro) e Ixbalanqué (Jaguar-Sol- 
-Oculto). Esses dois, depois da infância e de parte da juventude dedicadas à caça com zarabatana e às roças de milho, descobrem o apreço de seus pais pelo jogo de bola e serão, assim, convidados ao Xibalbá pelo mesmo motivo que seu pai e parceiro, ou seja, por incomodarem os senhores do $\mathrm{Xi}$ balbá com os seus frequentes jogos de bola sobre as suas cabeças.

Como Hunahpú (Um Zarabataneiro) e Ixbalanqué (Jaguar-Sol-Oculto) eram autênticos seres prodigiosos, conheciam as provações e burlas em que seu pai e parceiro haviam sido derrotados e, desse modo, conseguem triunfar nas provas todas e, assim, derrotar os senhores do Xibalbá e vingar a morte de seus progenitores. A vitória final se dá no mesmo campo de jogo de bola onde seu pai havia sido decapitado.

Mas em seguida a esses triunfos, os jovens gêmeos são mortos no Xibalbá. No entanto, eles pressentem a própria morte e escolhem sua forma: se atiram juntos, consciente e voluntariamente, em uma grande fogueira que pretendia ser uma armadilha feita pelos senhores do Xibalbá. Além disso, haviam antes persuadido os senhores do Xibalbá sobre o que fazer com seus corpos depois da morte: deveriam moer separadamente os ossos de cada um e jogá-los na fonte de onde brotam os grandes e pequenos rios. Desse modo, seus ossos não foram levados para longe, pois se assentaram no fundo da água e se transformaram em dois belos jovens, com as mesmas faces, mas haviam ressurgido como homens-peixes.

Como homens-peixes, os dois se trajavam como pobres miseráveis que dançavam e faziam grandes prodígios para os senhores do Xibalbá, como queimar casas e fazê-las ressurgir, se esquartejar um ao outro e depois ressuscitar. Esses prodígios maravilharam os senhores do Xibalbá, que pediram aos gêmeos para que os realizassem com eles próprios. O primeiro senhor do Xibalbá a ser morto foi Hun-Camé (Um Morte), senhor principal e governante do Xibalbá. No entanto, depois de matá-lo, os jovens gêmeos não o reviveram e ainda fizeram Vucub-Camé (Sete Morte) de prisioneiro, o qual se curvou e implorou por sua vida aos jovens gêmeos. Diante disso, todos os senhores do Xibalbá fugiram para um desfiladeiro e se amontoaram no fundo dele, onde foram fustigados por uma multidão de formigas. Os gêmeos vão até esse desfiladeiro e os senhores do Xibalbá os recebem prostrados, humildes e chorosos. Hunahpú e Ixbalanqué aceitam o pedido de clemência, mas impõem rigorosas condições aos senhores do Xibalbá. Eles não teriam grandes celebrações ou grandes oferendas e não receberiam sangue limpo. Teriam apenas coágulos de seiva e receberiam comales e panelas velhas, coisas frágeis e quebradiças. Só poderiam comer os filhos dos restolhos e dos ermos, mas não as nascidas e os nascidos na luz, isto é, os homens de milho que ainda seriam criados. Mesmo assim, não poderiam atacar repentinamente a qualquer pessoa, mas só os desprezíveis, pecadores, violentos, desgraçados e perversos. Depois disso, ao final dessa segunda parte do Popol vuh, os dois jovens rodeados de luz viajaram ao céu e se tornaram o Sol e a Lua e todo o céu se iluminou sobre o leito da Terra.

O início da terceira parte do Popol vuh é marcado por um episódio que, de algum modo, lhe é central, pois para ele concorrem as criações anteriores, a dos animais e as dos seres humanos de barro e de madei- 
ra, e dele derivam todas as histórias que serão narradas depois, seja nessa terceira ou na quarta parte da obra. Trata-se da criação dos homens e mulheres que serão os primeiros pais e mães dos narradores quichés do Popol vuh. Para fabricar essa nova gente e completar a criação com seres que iriam prover o sustento dos deuses, os seres prodigiosos, A-que-Concebe, O-que-Gera, O Criador, O Formador, Tepeu (Majestade) e Gucumatz (Serpente Emplumada) reuniram-se em conselho antes da aurora para buscar o que deveria compor a carne e sangue dos humanos. Optaram pelo milho. Convocaram, em seguida, os animais para procurar o milho e foram Yac (Raposa Cinzenta), Utiú (Coiote), Quel (Periquito) e Hohn (Corvo) que encontraram e recolheram espigas de milho amarelo e espigas de milho branco na Montanha do Sustento, em Paxil (Lugar da Fenda) e Cayalá (de Água Amarga), onde também havia cupuaçu, cacau e inumeráveis sapotis, graviolas, ciriguelas, muricis, sapotas-brancas e mel. As espigas foram moídas nove vezes por Ixmucané, a avó dos gêmeos que derrotaram os senhores do Xibalbá, e, junto com água descoberta também pelos animais, formaram a massa que comporia a carne dos seres humanos.

Assim surgiram quatro novos homens e primeiros pais dos quichés e dos outros povos maias: Balam-Quitzé (Jaguar Risonho), Balam Acab (Jaguar Noite), Mahucutah (O-que-Nada-Oculta) e Iqui Balam (Jaguar Lua). Esses novos seres, além de falar, conversar, ver, ouvir, andar, tatear e, principalmente, agradecer aos seus criadores, eram prodigiosos e se igualavam aos deuses. Eles podiam ver e conhecer sem obstáculos o que havia sob o céu e no leito da terra, ou seja, eles não precisavam se mover de onde estavam para conhecer tudo o que existia, pois seu entendimento e seu olhar atravessavam florestas, rochas, lagos, mares, montanhas e vales. Considerando que isso não era bom, pois desse modo os seres humanos não procriariam, não se multiplicariam, não semeariam e, assim, não haveria amanhecer, os deuses decidiram em conselho alterá-los um pouco, para que vissem somente o que estava perto: Coração do Céu bafejou sobre os olhos desses homens, embaçando-os como a um espelho. Os mesmos deuses criaram então quatro mulheres, que chegaram primeiro em sonho aos quatro homens, mas que passaram a existir quando eles despertaram. Assim, se formaram os primeiros quatro casais da gente de milho: Cahá-Paluna (Água Rubra do Mar) e Balam-Quitzé (Jaguar Risonho); Chomihá (Água Formosa) e Balam-Acab (Jaguar Noite); Tzununihá (Água do Colibri) e Mahucutah (O-que-Nada-Oculta); e Caquixahá (Água da Arara) e Iqui-Balam (Jaguar Lua).

A partir desse ponto, ainda em sua terceira parte, a narrativa do Popol vuh apresenta os episódios relacionados à multiplicação desses seres humanos, que ocorre na escuridão, antes do primeiro amanhecer dessa nova idade. Nessa época, se formaram diferentes tipos de gentes e com modos de vidas variados: gente de pele escura ou clara, com muitas faces ou formas diferentes, gente da montanha que vagava sem casa e era menosprezada pelas outras comunidades. Independentemente das diferenças, todos esperavam o amanhecer e ainda não possuíam seus deuses protetores. Mas cansados de esperar e impulsionados pela grande quantidade de pessoas e tribos, alguns resolveram sair para procurar 
os deuses protetores para si e seus descendentes e, também, procurar o que deveriam queimar diante desses protetores.

Tinham notícias da existência de uma cidadela mais antiga e os quichés, liderados pelos seus quatro primeiros senhores, Balam-Quitzé, Balam-Acab, Mahucutah e Iqui-Balam, e juntos com outras duas tribos quichés, os tamub e os ilocab, marcharam para essa cidadela em algum lugar do Oriente: Tulán-Zuiuvá ou Lugar dos Juncos e Sete Cavernas, que era governada por ninguém menos que Gucumatz (Serpente Emplumada). Lá, receberam seus deuses protetores, que lhes foram dados nessa ordem: primeiramente, Tohil foi dado a Balam-Quitzé, Avilix a Balam-Acab, Hacavitz a Mahucutah, Nicahtacah a Iqui-Balam; depois, os tamub receberam Tohil; em seguida, os ilocab também receberam Tohil. Depois dos quichés, chegaram os outros povos maias, como os rabinales e os cakchiqueles.

Desse ponto em diante, a narrativa se concentra em episódios que tratam de outras aquisições dos quichés durante sua estadia em Tulán-Zuiuvá, como o manejo e a produção do fogo, a atividade guerreira, o autossacrifício de sangue e o sacrifício de cativos de guerra a Tohil. Mas ali, lhes adverte Tohil, não era a casa deles e eles deveriam partir para procurar sua morada definitiva. Assim, juntamente com muitas outras tribos, os quichés partiram de Tulán-Zuiuvá antes do primeiro amanhecer, carregando seus deuses tutelares: Tohil, Avilix e Hacavitz. É, portanto, no caminho, enquanto habitavam montanhas e não tinham boa comida ou bebida, que os quichés e os outros povos testemunharam o primeiro amanhecer, que foi o mesmo para todas as tribos que existiam.
A partir dessa situação, a narrativa do Popol vuh entra em sua quarta e última parte, caracterizada pela fase final da migração e pela ascensão política dos quichés, que passaram a dominar outras comunidades maias. Para isso, os quichés ofereciam o próprio sangue ou o sangue de animais a Tohil, Avilix e Hacavitz, a quem pediam vigor e os meios e conselhos para derrotar as outras tribos. Ainda habitando montanhas, os quichés passaram a raptar pessoas que andavam sozinhas ou em duplas e sacrificá-las diante de Tohil e Avilix. Deixavam suas cabeças pelos caminhos, com sangue espalhado, e produziam pegadas de jaguar para que as tribos vizinhas pensassem que essas pessoas haviam sido devoradas por esses animais. Essa estratégia funcionou por muito tempo, mas as outras tribos se deram conta do que estava ocorrendo, reuniram-se em conselho e decidiram montar uma artimanha para capturar Tohil, Avilix e Hacavitz e adotá-los como seus próprios deuses tutelares. Mas o plano não é bem-sucedido e eles resolvem atacar os quichés em sua montanha. Embora muito mais numerosos, os 24 mil guerreiros aliados foram derrotados pelos prodígios de Tohil, que adormece os guerreiros inimigos antes de chegarem à montanha dos quichés, e pelos estratagemas dos quatro senhores quichés, que construíram uma paliçada e dispuseram bonecos adornados atrás dela, que os inimigos pensaram ser guerreiros. Além disso, fizeram armadilhas com vespas, zangões e mamangavas que atacavam e atordoavam os inimigos, que eram, então, atacados pelos homens e mulheres quichés. Desse modo, os quichés derrotaram todas as tribos de uma só vez e elas passaram então a lhes render submissão política. 
Depois de algum tempo, os quatro primeiros senhores quichés, Balam-Quitzé, Balam-Acab, Mahucutah e Iqui-Balam, pressentiram suas mortes. Reuniram seus filhos, lhes pediram para não serem esquecidos, lhes aconselharam a continuar a busca de suas moradas definitivas e deixaram um sinal de sua existência, um envoltório esplendoroso, que ninguém ousava abrir, mas apenas queimar incensos e resina de copal diante dele. Em seguida, desapareceram no alto da montanha Hacavitz e não foram enterrados por suas mulheres e filhos.

Após a morte dos pais, Qocaib (filho de Balam-Quitzé), Qoacutec (filho de Balam-Acab) e Qoahau (filho de Mahucutah) - Iqui-Balam não teve filhos - decidiram viajar ao Oriente, para receberam a investidura do poder e retornarem aos quichés como senhores legítimos. Chegaram ao reino de Nacxit, grande senhor juiz único de um grande domínio, que lhes deu as insígnias de poder: um pálio, um trono; uma flauta de osso, um tam-tam; pó resplandecente, argila ocre; presa de leão-baio, presa de jaguar; cabeça de veado, pata de veado; bracelete de couro, chocalho de concha; cabaça de tabaco, tigela de comida; e penas de papagaio, penas de garça-real. Além disso, os intitulou Ahpop (Guardião da Esteira) e Ahpop-Camhá (Guardião da Esteira da Casa do Recebimento).

Ao regressarem a Hacavitz, sua primeira cidadela, foram recebidos com alegria pelos tamub e ilocab, que também eram tribos quichés, e por todas as outras tribos ao retomarem os governos. A partir de então, o Popol vuh apresenta os locais em que os quichés se estabeleceram por algum tempo ou as cidadelas que fundaram durante a migração. Apresenta também o começo dos conflitos com os ilocab e o crescimento do poder dos quichés que narram o Popol vuh, ou seja, os quichés-cavec, que, junto com os quichés-nihaib e os ahau-quichés, constituem uma mesma comunidade política, formada por três casas grandes que, juntas, fundam e fortificam a cidade de Izmachí, que ainda não seria a sua morada final.

Já se encaminhando para o final, o Popol vuh narra a última fase da migração dos quichés, quando eles deixam Izmachí e se dirigem para Gumarcaah, sua capital e derradeira cidade, também chamada de Utatlán, como mencionamos antes. Quando isso ocorreu, tiveram por senhores principais a Cotuhá e Gucumatz (Serpente Emplumada), que governavam junto com muitos outros senhores. Eles seriam a quinta geração desde a origem da luz, desde a formação do ser humano. Mas parece que o crescimento do poder político e da riqueza tributária trouxe discórdias entre os quichés no momento de arranjarem seus casamentos e eles resolveram, então, se dividirem em mais linhagens do que as que já existiam. Dividiram o poderio dos senhores em 24 casas grandes: nove senhores eram cavec; nove senhores eram nihaib; quatro senhores eram ahau-quiché; dois senhores eram zaquic, que tinham duas linhagens, mas apenas uma casa grande.

O Popol vuh narra, em seguida, o crescimento contínuo do esplendor quiché, que se expressa na construção de templos e casas dos senhores e na multiplicação dos filhos de suas linhagens. Além disso, muitas das comunidades políticas teriam passado a se submeter voluntariamente aos quichés, por respeito aos prodígios que seus senhores realizavam e ao esplendor que irradiavam Gucumatz e Cotuhá, seus principais senhores e que possuíam natureza prodigiosa. Gucumatz era capaz de subir ao céu e descer 
ao Xibalbá, de tomar a natureza, forma e aparência de uma cobra, águia, jaguar ou poça de sangue.

Em suas últimas páginas, o Popol vuh traz os detalhes do poderio dos três ramos ou nações quichés - dos quichés que narram o Popol vuh, dos tamub e dos ilocab - com ênfase no primeiro grupo e seus três conjuntos internos de linhagens, ou seja, os cavec, que escrevem o Popol vuh, os nihaib e os ahau-quichés. É a época da quinta geração de senhores em diante, de senhores menos prodigiosos do que Gucumatz e Cotuhá. O livro termina com essa espécie de panorama dos senhores, linhagens e casas grandes, que vai até a época de produção do próprio Popol vuh, isto é, até meados do século XVI. Os últimos dessas 12 gerações de senhores mencionados são Oxib-Qeh e Beleheb-Tzi, que foram enforcados depois da conquista de Gumarcaah pelos espanhóis e indígenas nahuas e cakchiqueles. Os nomes dos soberanos da décima terceira e da décima quarta geração, que já pagavam tributos aos espanhóis, são mencionados em seguida, assim como a relação das nove linhagens e das nove casas grandes dos cavec e dos nihaib, e das nove linhagens e quatro casas grandes dos ahau-quichés. Trata-se do mapa político de uma nação derrotada e subordinada política e tributariamente, mas não destruída. Uma afirmação ou manifesto quiché da vigência de sua estrutura comunitária no período colonial, assim como do papel das histórias e da cosmologia contidos nela.

\section{CONVITE À LEITURA}

Como se pode observar nessa breve síntese, a perspectiva dos maias-quichés que produziram o Popol vuh abrange muito mais do que a história de seu grupo, pois a entrelaça tanto com a história de outros grupos maias como com a história de outros povos indígenas da Mesoamérica, como os nahuas. Além disso, entrelaça essa história grupal e regional com a de todas as tribos e nações indígenas contemporâneas a eles, aos maias-quichés, pois todas seriam compostas pelas mulheres e homens de milho cujos antepassados viram o mesmo e primeiro nascimento deste Sol e Lua atuais. Vai ainda além. Aponta que essa grande história ou idade dos seres humanos de milho não é a única, pois o mundo conheceu humanidades e sóis anteriores, dando a entender que o mundo-idade atual não é um cenário pronto, acabado e estável, onde se desenrola a história dos homens e mulheres de milho. Ao contrário - e isso está explicitamente presente em vários outros textos maias e mesoamericanos -, o mundo atual continua a ser instável e a estar sujeito a cataclismos e reviravoltas que irão transformar a sua face e as sociedades humanas e não humanas que o habitam. Em outras palavras, diferentemente da cosmologia judaico-cristã, a feitura e produção do mundo não estão apenas em seu início, mas são um processo contínuo, cumulativo e marcado por grandes e constantes transformações e metamorfoses no que chamamos mundo natural e social. Talvez isso nos pareça hoje bastante familiar e razoável como forma de olhar para o mundo, pois coincide com ideias centrais às cosmologias científicas em vigor. No entanto, seu conteúdo é altamente contrário ao da cosmologia judaico-cristã com a qual o pensamento maia se defrontou a partir do século XVI e que vigorou no mundo ocidental com exclusividade até muito pouco tempo atrás. 
Não bastasse essa amplíssima perspectiva temporal, social e cosmológica, os maias-quichés nos mostram ainda uma ampliação em outra direção: a dos agentes que participam dessas histórias e cosmologias. Além dos deuses e homens, o mundo dos quichés conta com a participação de muitos outros agentes, como seres humanos prodigiosos, mortos, guardiões das florestas, montanhas e rios, animais, vegetais e até mesmo objetos. Vale notar que os animais e objetos, por exemplo, são apresentados no Popol vuh como agentes completos, ou seja, com vontade, pensamento e linguagens próprios; e não como entes que seriam animados ou manipulados pelos deuses para realizar os seus desígnios. Além disso, assim como em outras cosmologias ameríndias, a condição existencial desses agentes deve-se mais a um estado ou posse de um tipo de corpo ou pele do que a algum tipo de essência fixa e imutável. Sendo assim, embora perigoso, as fronteiras entre esses estados podem ser transpostas quando os corpos ou peles são alterados: os deuses podem se tornar animais; os animais podem se tornar humanos; os humanos podem se tornar montanhas ou deuses etc.

Essas são algumas razões para ler o $P o$ pol vuh e empreender uma experiência que é singular, pois nos traz a sensação de adentrar, pouco a pouco, formas de pensamento que surpreendem, enfatizam aspectos inesperados da realidade e constroem personagens, tramas, tensões e desfechos narrativos absolutamente originais quando comparados aos que se encontram presentes nas histórias e cosmologias da antiguidade clássica ou judaico-cristã. Assim, e como muitas outras histórias e cosmologias ameríndias, o Popol vuh nos mostra que é possível construir e narrar outros mundos, habitados por outras humanidades, que não são em nada inferiores às humanidades de matriz europeia que hoje habitam e dominam politicamente o continente americano. São apenas humanidades diferentes e que foram, em enorme medida, despojadas de suas autonomias políticas e territoriais nos últimos cinco séculos. Essa relativa vitória do mundo ocidental e cristão sobre essas humanidades indígenas é uma vitória bélica e política, que lhes impõe adotar ou negociar com uma forma de pensamento que não é superior ou mais avançada que a deles próprios. Sendo assim, os povos e nações indígenas não são resquícios do passado, sobreviventes imutáveis de uma etapa anterior em uma história universal, etapa essa que já teria sido percorrida e superada pelas sociedades cristã-ocidentais. Esses juízos de valores ou classificações baseados na ideia de progresso são, claramente, parte de um discurso, de uma ideologia criada e imposta como verdade histórica pelas próprias sociedades cristã-ocidentais que hoje controlam social e politicamente todos os Estados-nações do continente americano, onde essas humanidades indígenas continuam e continuarão a viver. Infelizmente, a relação entre as sociedades nacionais de matriz europeia e as populações indígenas continua a ser marcada pela violência contra essas populações, pelo despojamento de suas terras e pelo genocídio premeditado dessas humanidades indígenas, as quais, aos olhos de muitos ocidentais, são apenas povos atrasados e decadentes que atravancam o desenvolvimento suicida da civilização técnico-industrial-capitalista e que mancham a existência de Estados-nações que deveriam ser, segundo essa visão prepotente e narcisista, homogêneos e uniformes em termos étnicos e culturais. 


\section{EDIÇÕES BRASILEIRAS EM PORTUGUÊS DO POPOL VUH}

Temos a fortuna de contar com duas edições recentes e primorosas do Popol vuh em português em nosso país.

A edição com organização e tradução de Gordon Brotherston e Sérgio Medeiros foi a primeira publicada em português no Brasil, em 2007, e supriu essa grave lacuna de nosso mercado editorial. Os dois estudiosos se basearam primordialmente na tradução ao inglês do maia-quiché de Munro Edmonson, do começo dos anos 1970, mas eles também consultaram outras traduções a idiomas ocidentais, além do próprio texto em maia-quiché, que consta nessa edição ao lado da versão em português. Nessa edição, destacam-se 0 imenso zelo e acuidade com a palavra de Sérgio Medeiros, que é poeta e ensaísta, e o vastíssimo conhecimento de Gordon Brotherston, um dos mais destacados conhecedores mundiais dos códices mesoamericanos e das histórias e cosmologias ameríndias de modo geral.

A edição com tradução de Josely Vianna Baptista foi publicada recentemente, em 2019, e se baseou primor- dialmente na mais famosa e talvez mais lida tradução ao espanhol do Popol vuh, a de Adrián Recinos. Partindo dessa versão ao espanhol, a tradutora realizou um trabalho excepcional e muito robusto, pois comparou a versão de Adrián Recinos com mais oito traduções do Popol vuh a línguas ocidentais e, também, ao próprio texto em maia-quiché. 0 resultado é uma tradução crítica de alto valor para aqueles que se interessam pelas pesquisas sobre os maias e sobre o Popol vuh. No entanto, toda essa carga de estudos e debates é sabiamente apresentada, nessa edição, em notas que se encontram após 0 texto em português, 0 qual é lido de modo fluente e tranquilo. Além disso, contribui para essa leitura fluente a apresentação de traduções ao português dos nomes em maia-quiché dos deuses, animais e plantas, pois muitos desses animais e plantas nos são familiares, já que os maias-quichés habitam ambientes tropicais ou tropicais temperados, semeIhantes aos que existem em boa parte de nosso país.

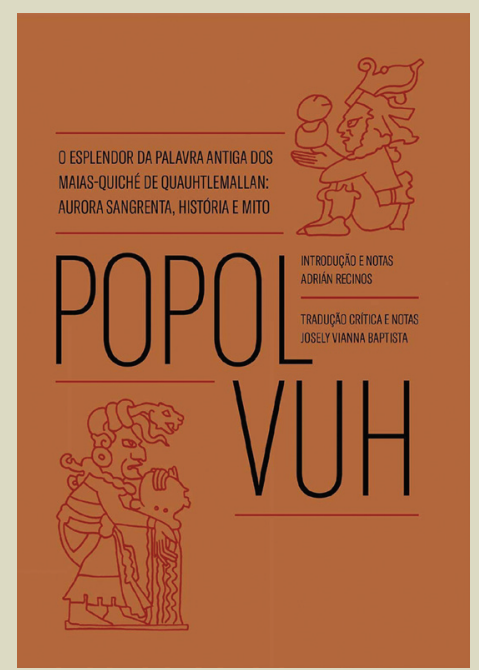

Popol vuh - O esplendor da palavra antiga dos maias-quiché de Quauhtlemallan: aurora sangrenta, história e mito, tradução crítica e notas de Josely Vianna Baptista, São Paulo, Ubu Editora, 2019, 384 pp. 